\title{
TERRITORIOS DE IDENTIDADE NOS TERRITÓRIOS DE PLANEJAMENTO
}

\section{Territories of Identity in the Territories of Planning}

Prof ${ }^{a}$ Maria Augusta Mundim Vargas

Universidade Federal de Sergipe, Nucleo de Pos Graduação Em Geografia Av. Marechal Rondon s/n - NESA, Rosa Elze, CEP: 49100-000 - Sao Cristovão, SE - Brasil Tel/Fax: (+55 79) 2105678 / 21056782 - amundim@infonet.com.br

\section{aaAaa}

\begin{abstract}
Resumo
O artigo discute as possibilidades de construção de identidades territoriais a partir da definição governamental de Territórios de Planejamento questionando se estes seriam conformadores das materializações culturais. Apresenta o resultado de pesquisa realizada, em 2009, em todos os municípios do estado de Sergipe. À margem dessa discussão e no curso da pesquisa, esboçou-se uma cartografia que se presentificou concomitante à definição teórico-metodológica como uma contribuição à pequena produção da cartografia cultural no âmbito da Geografia. A cartografia é tomada neste artigo como exposição de um estudo de caso.
\end{abstract}

Palavras-chave: Territórios de Planejamento; Territórios; Culturas; Identidades; Cartografia cultural.

\begin{abstract}
[The article discusses the possibilities of identity construction from the territorial government's definition of Planning Territories questioning whether they were determinant of cultural identity constructions. It presents the results of research carried out in 2009 in all municipalities in the state of Sergipe. Alongside this discussion and in our research, concurrently with theoretical and methodological definition, cartography was laid out as a contribution to such a small cartographic production of the cultural geography. Cartography is employed in this article as an explanatory tool of a case study.
\end{abstract}

Keywords: Planning of Territories, Territories, Cultures, Identities, Cultural cartography.

\section{Resumen}

El articulo trata de las posibilidades de construcción de identidades territoriales a partir de la definición gubernamental de Territorios de Planeamiento cuestionando si estos serían conformadores de las materializaciones culturales. Presenta el resultado de investigación realizada, en 2009, en todos los municipios del estado de Sergipe. Aparte de esa discusión y en el curso de la investigación, se ha enseñado una cartografía que se ha presentado concomitante a la definición teórico-metodológica como una contribución a la pequeña producción de la cartografía cultural en el ámbito de la Geografía. La cartografía es tomada en este artículo como muestra de un estudio de caso.

Palabras-clave: Territorios de Planeamiento; Territorios; Culturas; Identidades; Cartografía cultural.

\section{aaCaa}

Revista da ANPEGE, v. 7, n. 1, número especial, p. 99-109, out. 2011.

ISSN 1679-768 X @ @ 2003, Associação Nacional de Pesquisa e Pós-Graduação em Geografia. Todos os direitos reservados. 


\section{INTRODUÇÃO}

A recente criação de Territórios de Planejamento em alguns estados brasileiros incorporou no processo de divisão aspectos culturais até então desconsiderados como dimensão para a regionalização. Em Sergipe, esse novo padrão de regionalização foi instituído pelo Decreto no 24338 de 20/04/2007 e, pela primeira vez, a cultura é internalizada no planejamento do desenvolvimento, considerada como um dos eixos de inclusão social pela renda.

Com a intenção de melhor conhecer a realidade do Estado com vistas à elaboração de políticas de valorização das culturas locais, a Secretaria de Planejamento solicitou à Universidade Federal de Sergipe a realização de um estudo sobre "Identidade, Cultura e Desenvolvimento dos Territórios sergipanos: Inventario cultural e elaboração de um atlas da cultura sergipana"ii (VARGAS; NEVES, 2009). Este estudo resultou em ampla pesquisa em todos os 75 municípios de Sergipe e cujos resultados são aqui parcialmente apresentados.

Parcialmente, porque neste artigo apresentamos apenas um resumo da pesquisa e privilegiamos as reflexões decorrentes das indagações que perpassaram a sua consecução, quais sejam: i) seria possível realizar um atlas da cultura atado a realização de um inventario? ii) seriam os Territórios de Planejamento identitários e conformadores das materializações culturais? Tais indagações exigiram reflexões e posicionamentos sobre cultura e identidade e sobre o território que estão aqui diluídos no balizamento metodológico, na espacialização das expressões culturais e nas reflexões sobre a construção dos territórios identitários, as partes constitutivas deste artigo.

\section{DELINEAMENTOS: TERRITÓRIOS DE PLANEJAMENTO, CULTURA E IDENTIDADE}

A recente divisão do Estado em Territórios de Planejamento e, considerando a intencionalidade de conformação de Territórios de Identidade, consiste em um novo padrão de regionalização que, por um lado, supera o eixo de promoção do desenvolvimento ancorado no modelo de turismo de praia e sol iniciado nos anos 1980 e, por outro, instiga a continuidade da abordagem cultural, sobretudo, por vivenciarmos, pela primeira vez, a cultura como dimensão do planejamento do desenvolvimento.

Todavia, a polissemia dos termos espaço e território não se restringe ao uso banal e corriqueiro de suas aplicações como limites, jurisdições, como delimitadores de áreas fluidas, como os eventos das ruas, das gangs e das prostitutas e, até os espaços e territórios mais subjetivos como da mente e das emoções, mas também no âmbito das abordagens da vertente econômica, que entende o território como recurso oriundo da relação capital-trabalho, que permite a análise da divisão territorial do trabalho, da vertente ambientalista focada na conflituosa ralação sociedade-natureza, nos territórios e espaços impactados, poluídos, de preservação, etc.

Para discutirmos os territórios e a organização dos espaços do Estado de Sergipe no âmbito da Geografia, adentrarmos no corpo de seu pensamento em que pese a constituição e a evolução de espaço e de território como categorias centrais de sua análise. A despeito do desenvolvimento dessas categorias por diversas correntes de pensamento, ora uma anulando ou secundarizando a outra, ora aproximando os sentidos, há um consenso de que o território se distingue por ter seu sentido mais associado às idéias de domínio e de gestão de uma dada área.

Raffestin (1993) foi quem melhor nos trouxe essa distinção, dirimindo controvérsias sobre os elementos constitutivos do espaço e do território. Ele mostrou-nos que o território se forma a partir de relações de poder, mas não apenas aquelas relações advindas das estruturas dos Estados ou de grupos em particular, mas também as relações de poder que se formam e são praticadas em todos os níveis da estrutura social. O poder, com efeito, permeia todas as relações em expressões e formas múltiplas, configurando os territórios. Assim, o território se constitui a partir do espaço, "se apóia no espaço", mas não é o espaço pois “o espaço antecede o território". São, portanto, as relações sociais e, nelas, as relações sócio-culturais exercidas pelos indivíduos, pelos grupos e 
pelas sociedades que produzem os territórios através de múltiplas formas de expressão, de gestão, de domínio, de apropriação, de identidade, de pertencimento, etc.; etc.

Isto posto, entendemos o espaço, tal como Milton Santos, constituindo o "conjunto indissociável, solidário e contraditório do sistema de objetos e do sistema de ações [...] são as formas, as funções, a estrutura e os processos desenvolvidos pelos sistemas de objetos e pelos sistemas de ações" (1999, p.50-51). Assim, no âmbito dessa análise interpretativa, o espaço se presta para observarmos sua organização e o território as relações sócio-culturais empreendidas pelos diversos atores que imprimem ações, movimentos, expressões e manifestações que conformam Sergipe e a sergipanidade, a identidade dos sergipanos.

De forma mais objetiva, direcionamos nossa análise focando os territórios identitários e os territórios de planejamento. Os territórios identitários são constituídos pela valorização simbólica de inúmeras manifestações e por incontáveis grupos sociais que, ao se expressarem, ou seja, ao exercitarem e praticarem suas manifestações conformam territorialidades e tornam os territórios múltiplos e flexíveis, independentemente da forma que se expressam. É o caso, por exemplo, das diversas festas que se materializam, cíclicas ou acíclicas, mas todas, a partir de relações sócio-culturais, aí embutidas valorização, herança, pertencimento, mas também, conflitos, disputas, rivalidades, etc.; etc., podendo-se citar desde as comemorações religiosas e pagãs de padroeiras e padroeiros, aos palcos de forrós ocorrentes, ambos, na maioria dos municípios sergipanos. É o pulsar e a dinâmica plural do território que se multiplica como um continuum (Haesbaert, 2008) em várias formas e compartilhamentos.

Por outro lado, o território entendido na perspectiva do desenvolvimento, internalizado como variável nas políticas de intervenção nas relações sociais e econômicas constitui os nomeados Territórios de Planejamento que, muito recentemente foram concebidos como ferramenta estratégica do planejamento do desenvolvimento. Embora planos de governo tenham sido propostos desde a década de 1950, com o Plano de Metas de JK, a associação "território e identidade", foi incorporada muito recentemente nas políticas públicas pelo Plano Plurianual do governo federal em 2004 e, pelo governo de Sergipe, em 2007, instituindo oito Territórios de Planejamento. Com essa condução, a valorização da cultura e diversidade das expressões culturais é incorporada como um dos mecanismos de promoção do desenvolvimento das instituições governamentais, como mais um instrumento de ação e, nesse sentido, de controle institucional.

O termo cultura, tal como território, tem uma longa história no campo das ciências humanas. Desde o século XIX Tylor (E. B.Tylor, 1871, apud Dortier, 2008), delimitou-a como o conjunto de crenças, valores, costumes, ideologias, saberes e práticas que caracterizam uma sociedade. Tal entendimento, como se "a cultura" pairasse acima das práticas concretas dos atores sociais, conferindo-lhes sentido e racionalidade, como se fosse um todo coerente e estruturado que definisse o comportamento e as percepções dos membros de uma sociedade, foi superado, com destaque para a obra de Geertz (1989). Este nos mostra a existência de múltiplas culturas nas sociedades. As culturas são marcadas por diferenças de classe, por exemplo, e também, pelo fato dos atores sociais interpretarem e conferirem sentido às culturas, as quais devem ser vistas como conjuntos de discursos ou textos passíveis de diferentes formas de apropriação e interpretação.

Essa postura interpretativa, ou semiótica, da cultura tem variadas implicações empíricas e teóricas. Naquilo que nos concerne nesta reflexão, cabe destacar que as manifestações culturais levantadas não são consideradas como a expressão de um todo coerente e estruturado ao qual poderíamos chamar de "cultura sergipana", base da identidade sergipana. Elas são parte de um universo simbólico que, se não podemos considerar como desestruturado, têm diversos eixos e lógicas estruturantes, alguns dos quais competem entre si, conferindo-lhe uma instabilidade intrínseca e indepassável. Universo simbólico que, por economia de linguagem, chamamos de cultura, mas que seria melhor expresso pela forma plural, culturas, ou ainda, pelo termo expressões culturais. 
As expressões, manifestações ou práticas culturais têm uma história, fruto de um processo de longo ou médio prazo, que se materializam em produtos materiais, práticas gestuais ou linguajares, atividades coreográficas e musicais, vínculos espaciais, religiosos, modos de pertencimentos, etc. Já as identidades são os discursos e as relações empreendidas que fortalecem sentimentos de pertencimento entre os membros de uma sociedade. As identidades podem ser construídas a partir de expressões culturais específicas, adotadas ou não por todos ou por uma parte da população.

As identidades, ou melhor, os processos de identificação, são estabelecidos a partir de relações dialógicas com "outros" imaginários ou reais. Nesse sentido, é importante sublinhar, como faz Stuart Hall (1999), que as identidades são sempre múltiplas, multi-referenciadas, seja no plano simbólico-cultural, material ou territorial (Haesbaert, 2008); as identidades são híbridas (Canclini, 2003), nas quais os sujeitos agenciam diversas tradições culturais, formas de pertencimento e de auto-identidade.

A experiência vivida pela população tem influência certamente nas suas maneiras de conceber e perceber o mundo. Assim, práticas culturais marcam os membros de uma comunidade com uma marca indelével embora nem sempre visível ao primeiro olhar. Em suma, a concepção de 'culturas' que animou a realização dessa pesquisa pode ser resumida nas seguintes premissas: a) as manifestações/expressões/práticas culturais não estão necessariamente vinculadas a identidades e à territórios identitários de planejamento, embora marquem as experiências e, em geral, participem do processo de percepção do mundo pelos sujeitos; e b) as culturas têm a ver tanto com o passado (a tradição) como com o presente-futuro, criação ou ressignificação de práticas culturais do passado e/ou do além fronteira.

Assim, superamos a primeira questão posta na introdução com o entendimento de que a cultura é múltipla, dinâmica, em constante produção e (re) significação e, portanto, os limites do inventário deveriam estar bem claros de forma que não se apresentassem como um levantamento exaustivo e pretensiosamente final da cultura sergipana. Tais limites serão expostos na descrição da metodologia. A segunda questão é mais complexa posto que o trabalho de levantamento das práticas e manifestações culturais não nos permite acessar automaticamente a identidade do grupo que a produz. Tal tarefa exige a apreensão, dentre outros, das representações constituídas pelo grupo em torno da "produção" e dos laços de pertencimento para com o que se produz. Isso significa dizer que o resultado desse levantamento deve ser apreendido de forma aberta e flexível, como indicativo de inúmeras perspectivas, desde as mais simples intervenções de valorização aos necessários aprofundados e contínuos estudos que a cultura demanda.

\section{BALIZAMENTOS INSTRUMENTAIS}

Tais premissas balizadoras foram importantes para o delineamento metodológico do trabalho de campo e para a implantação cartográfica. A partir delas, foram definidas como categorias norteadoras da pesquisa: i) manifestações culturais tradicionais enraizadas; ii) manifestações culturais ressignificadas/contemporâneas.

Outro aspecto a ser considerado diz respeito à distinção tipológica entre tradicional e popular, inicialmente proposto pela SEPLAN. Ela esvaziou-se pelo risco de apreender o popular como manifestação pop ou de massa. Entendemos o termo popular como substantivo, chão promotor de manifestações "lidas" como tradicionais e contemporâneas. Dessa forma, as manifestações tradicionais enraizadas traduzem, nesta pesquisa, aquelas herdadas e mantidas tal como apropriadas no passado e, as manifestações ressignificadas/contemporâneas aquelas que em suas evoluções apresentam variações na composição e na estrutura, mas também o novo, recentemente apropriado.

Quanto ao balizamento instrumental do inventário etnográfico, há que assinalar um aspecto importante da interseção entre as categorias e a cartografia. O etnógrafo, como colocado por Geertz (1989, p. 29) "inscreve" o discurso social, anota-o e "ao fazê-lo, ele o transforma de acontecimento 
passado, que existe apenas em seu próprio momento de concorrência, em um relato que existe em sua inscrição e que pode ser consultado novamente". Almeida (2008, p.332) reforça essas colocações afirmando que o levantamento "evidencia a etnoterritorialidade, na qual se destaca a estreita relação de uma cosmologia com o lugar".

Tal balizamento possibilitou a estruturação de um roteiro de entrevistas que privilegiou a identificação das manifestações e seus produtores, a origem, evolução e dinamismo, assim como o significado para os participantes. Após a realização das entrevistas, foi elaborada uma ficha para cada município, um quadro síntese com exposição da lista de expressões levantadas, "enquadrando-as" na tipologia das grandes categorias tradicional enraizada ou ressignificada/contemporânea, pelo local e data de ocorrência e, pela ordem de importância.

Foram realizadas 349 entrevistas nos 75 municípios do Estado de Sergipe nos meses de julho e agosto de 2009, resultando uma média de 4,6 entrevistas por município. O levantamento foi realizado com 1) representantes de órgãos municipais ligados à cultura;2) historiadores e intelectuais dos municípios e, 3) com grupos ou pessoas produtores de expressões culturais. Estes últimos proporcionaram a realização do que se definiu como "entrevista foco", pois detalharam e contextualizaram apenas a manifestação/expressão/prática por eles produzida.

Em todos os municípios o primeiro contato foi com as prefeituras, junto aos órgãos e pessoas gabaritadas. Inicialmente, foi-lhes solicitado enumerar espontaneamente as manifestações que expressam o município, que mobilizam os munícipes, que traduzem a imagem do lugar, estabelecendo desta maneira, uma ordem de importância. Assim, como cada município foi coberto por dois pesquisadores, o segundo se dirigia às pessoas indicadas, seja na sede ou nos povoados e, o primeiro permanecia no órgão da prefeitura detalhando informações ou, liberado, complementando as entrevistas com pessoas indicadas ou identificadas, as chamadas "entrevistas foco". É evidente que o roteiro detalhado de informações não se completou para todas as manifestações levantadas posto que muitas delas foram referenciadas como "do passado" e, outras, não se inserem em cadeia produtiva, geradora de renda tal como solicitado no item sobre dinamismo do roteiro, como é o caso de festas cívicas e folguedos. O fato é que o material coletado gerou um importante documento, pois proporcionou a confecção de uma coletânea que nomeamos Cadernos dos Municípios, com a transcrição das falas dos entrevistados, acrescidas de suas expressões sobre o lugar e de uma breve descrição dos pesquisadores sobre suas impressões quanto a receptividade e a paisagem urbana e rural do município. Com isso, a riqueza das falas foi resguardada neste material.

A produção cartográfica partiu da ficha síntese de cada município e em seu processo foram sendo construídas matrizes agrupando em sequência, os tipos de manifestações e padronizando as terminologias levantadas. Os mais de 600 tipos de manifestações e expressões levantadas foram agrupadas em 17 tipos tradicionais enraizadas e em 12 tipos ressignificadas/contemporâneas, constituindo os grandes agrupamentos. A Matriz Final foi enriquecida após a leitura das descrições, ou seja, da fala dos entrevistados. Dessa forma, ao descrevermos a construção da Matriz Final estamos, em verdade, traduzindo um processo de construção de sucessivas matrizes, um processo evolutivo que traduz a dinâmica do processo de mapeamento, mas sem perder o registro da linguagem diferenciada para as manifestações e a diversidade de práticas e expressões levantadas.

Para exemplificar esse processo a figura 01 traz a matriz simplificada de um dos Territórios de Planejamento. Optou-se por tal implantação de forma a facilitar a visualização do conjunto de manifestações levantadas, bem como agrupamentos e especificidades. Com efeito, a maior densidade de determinada manifestação nas linhas verticais sinaliza sua ocorrência generalizada e, a maior densidade de cores nas linhas horizontais indica a diversidade de manifestações nos municípios. 


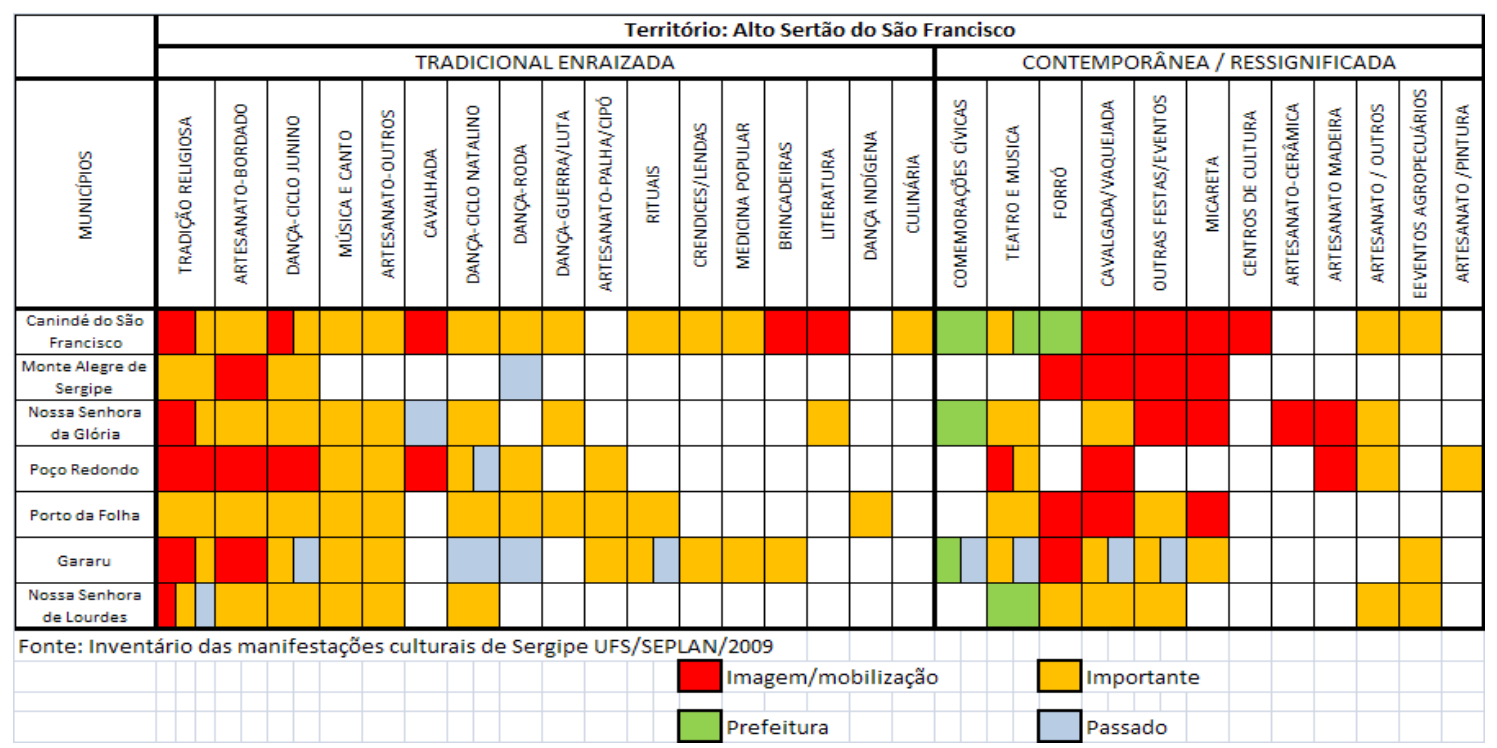

Figura 1-Manifestações culturais - Território Alto Sertão do São Francisco

Com o auxilio das cores indicando grau de importância, observa-se que no Território do Alto Sertão do São Francisco as manifestações tradicionais enraizadas são mais numerosas e representam significativas expressões, mas é o presente, ressignificado/contemporâneo que sobressai. A nucleação das manifestações e expressões do Alto Sertão do São Francisco permite sinalizar alguns aspectos. Sem secundarizar as manifestações e expressões importantes (amarelo) e, aquelas pontualizadas, únicas e singulares, a ênfase no questionamento sobre as manifestações que traduzem a imagem/ mobilização, transporta o simbolismo do Alto Sertão do São Francisco para as Vaquejadas, Cavalgadas, Micaretas, festas e eventos, (contemporâneas) e para as tradições religiosas e artesanato de bordados (tradicionais). Afora as festas cívicas, as prefeituras vêm cada vez mais assumindo total ou parcialmente eventos agropecuários, festas especiais (como a festa do Quiabo e as micaretas) e, também, festividades (shows) de padroeiras (os). Essa realidade foi observada em todos os demais Territórios.

O processo de construção cartográfica se completa com a elaboração de 33 cartas temáticas que, reproduzindo as 4 (quatro) indicações da legenda, que proporcionaram a espacialização das manifestações culturais levantadas e a apreensão das semelhanças e diferenças, bem como o registro das marcas do passado, fruto das lembranças dos entrevistados. O processo de espacialização das manifestações, todavia, tomou como referencial para implantação a manifestação mais importante, ou seja, de maior expressão, representada pela cor/significado vermelha.

Para o grupo de manifestações tradicionais enraizadas mais representativas foi definido pela elaboração de cartas que espacializassem suas ocorrências "no passado". Essa decisão foi tomada com intenção de espacializar "o avesso do presente", pois são de grande valia para a compreensão das manifestações ressignificadas/contemporâneas, como recurso para a apreensão do que se constrói e do que se produz no presente.

Assim, como exemplo, mostramos as cartas temáticas de Espetáculo e Dança do Ciclo Junino, como representativas nessa exposição metodológica, das manifestações tradicionais enraizadas do presente e do passado e, a carta de Forró, inserido no grupo de Festas e Eventos, como representativa das manifestações ressignificadas /contemporâneas, constituindo as figuras 02 e 03 . O texto que acompanha as cartas temáticas enfatiza a distribuição, a quantidade, as singularidades e as relações de semelhança das manifestações culturais entre os municípios e os Territórios de Planejamento, constituindo, com efeito, indicativo para a análise interpretativa da cultura sergipana. 
Em Sergipe, as festas, danças e rituais do ciclo junino são fortemente espacializadas e foram traduzidas como imagem, como evento mobilizador ou muito importante em 64 dos 75 municípios sergipanos. As chuvas de São José, em março, proporcionam o plantio, mas é no mês de junho que a colheita, principalmente do milho, é agradecida e festejada. Assim, a ambiência dos festejos rurais migrou para povoados e sedes e a decoração, trajes e os pratos típicos acompanharam o movimento, ritmados pelas danças entoadas pelas sanfonas, zabumbas e triângulos.
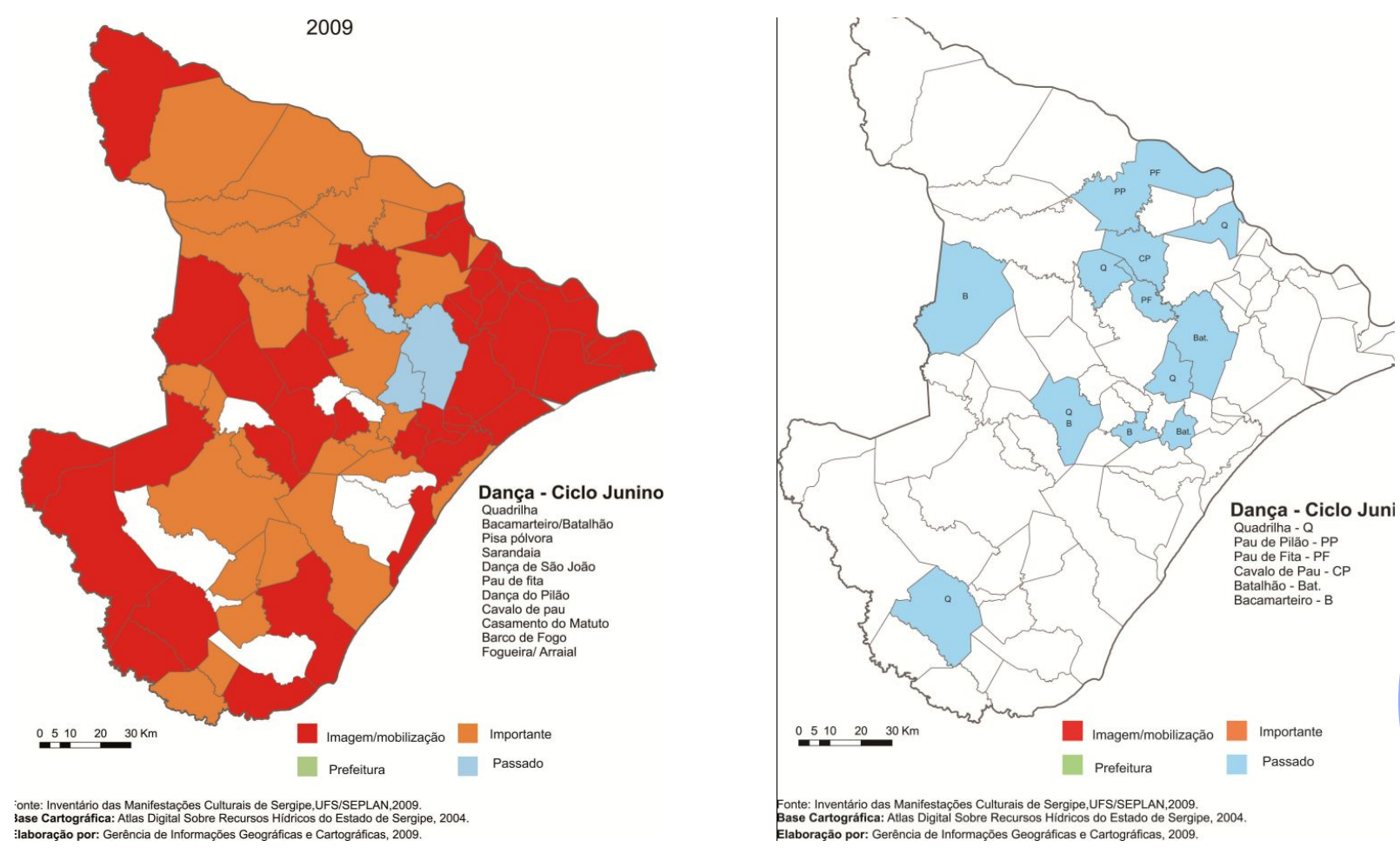

Figura 2 - Manifestações culturais - Espacialização das tradições enraizadas - dança Ciclo Junino atuais e do passado

Os santos reverenciados são quatro: Santo Antônio, São João, São Pedro e São Paulo, sendo São João o mais festejado, pois suas manifestações explodem em quadrilhas, fogos, arraiais, etc,. Dentre as manifestações mapeadas, a quadrilha destaca em número de ocorrência e como imagem/ mobilizadora de 26 municípios. A não ocorrência de quadrilhas em 29 municípios deve-se, sobretudo, às mudanças ocorridas nos festejos juninos após a metade da década de 1980. Assim, em nosso mapeamento, registra-se que muitas quadrilhas expressas na cor vermelha (imagem/mobilizadora) inserem-se na nova versão de produção mais voltada para a "originalidade e novidade" do que para a manutenção dos passos tradicionais. Igualmente, em muitos municípios em que a quadrilha não foi registrada, apreendemos respostas do tipo "a gente brinca São João" referindo-se à formação espontânea como se "dançar" não implicasse na formação organizada e sujeita as novas regras dos concursos que cada vez mais estilizam a manifestação. Contudo, a cultura é viva e essa é a nossa realidade presente.

As danças do Pilão e do Cavalo de Pau foram captadas como manifestações "do passado" que não ocorre mais em dois municípios e, em outros três, os espetáculos e danças do ciclo junino como um todo. Cremos, todavia, que a tradição de ascender fogueiras, assar milhos e soltar fogos, entoar cantos e passos, permanecem, sem espetáculos organizados nestes e em todos os municípios de Sergipe. 


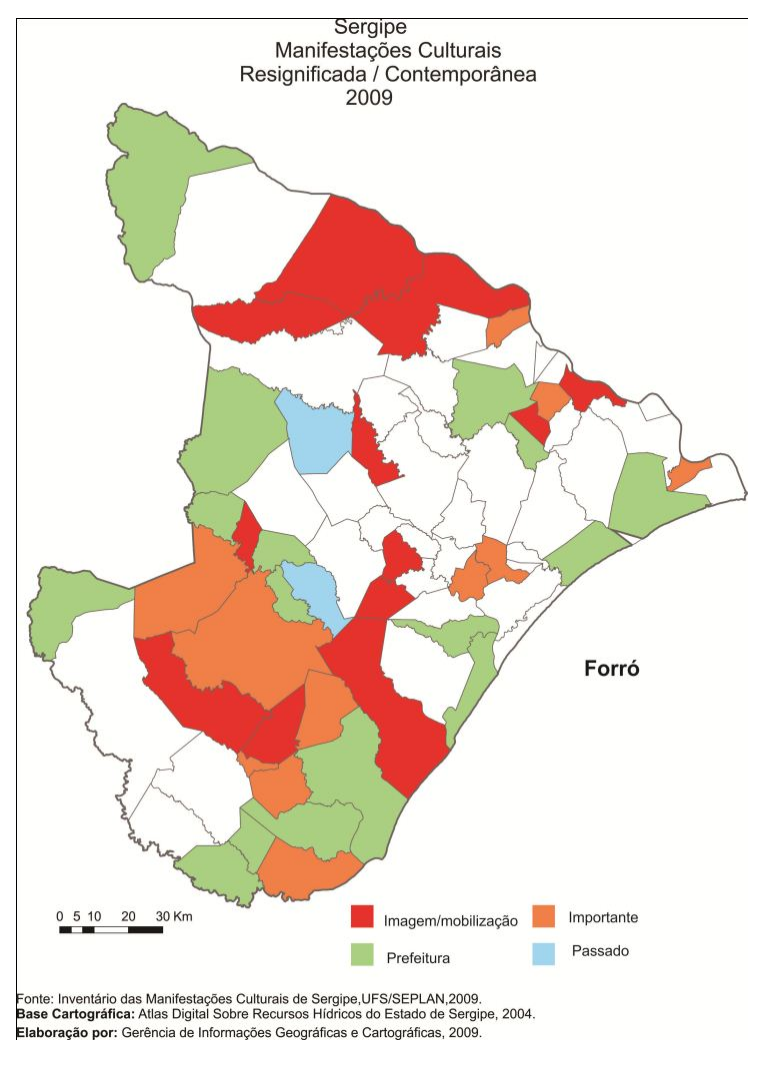

Figura 3 - Manifestações culturais - Espacialização das tradições ressignificadas/contemporâneas - Forró

Com relação à espacialização dos Forrós, uma retrospectiva histórica do deslocamento dos arraiais juninos para praças de eventos demarca a década de 1990 como o período transformador do convívio comunitário à explosão de massa. Tal movimento, gestado na década anterior, teve como marco a visibilidade do festejo junino em Campina Grande - PB, logo apropriado em Sergipe nas cidades de Areia Branca e Estância, seguidas de Aracaju. Em mais da metade dos municípios sergipanos (39), ocorre forrós que pelas dimensões social, simbólica e econômica de suas representações são, paulatinamente, assumidos pelos governos municipais (16) que em cadeia, solicitam e recebem cada vez mais, apoios financeiros do governo do estado.

A geração de empregos temporários ou de renda extra é garantida para uma serie de segmentos especializados e para um número considerável de sergipanos, a despeito de contrato com músicos de renome nacional com maior visibilidade na festa. São mais numerosos e representativos os beneficiários pelas rendas adquiridas da confecção de roupas e fogos, pelos comerciantes de tecidos, adereços e calçados, pelos vendedores ambulantes, para os bares e restaurantes, para os agricultores que têm a certeza do consumo de safra de milho e amendoim, mencionando ainda o acréscimo no consumo de macaxeira e derivados; para os hotéis e, ainda, dos inúmeros serviços de apoio remunerados com pagamento extra, tanto nas atividades diretas das festas, como nas atividades indiretas de transporte, postos de gasolina, acomodação, alimentação dos participantes, assistentes, brincantes e trabalhadores dos forrós.

\section{REFLEXÕES: DA CARTOGRAFIA CULTURAL, DAS CULTURAS E DAS IDENTIDADES}

Como vimos, as culturas interpelam os sujeitos de duas maneiras diferentes: através do agenciamento de práticas passadas e presentes e, ao mesmo tempo, através de projetos formatadores de 
práticas futuras. Essa dupla vinculação das culturas torna a sua abordagem algo complexa e estimulante ao tempo em que justifica as intenções de execução dessa pesquisa, em consonância com os propósitos do governo do Estado de Sergipe, manifestados pela Secretaria de Planejamento, de conhecer as manifestações culturais de Sergipe como potencialidades e estratégias definidoras de políticas de inclusão e também, como chão identitário dos Territórios de Planejamento.

Isso significa ainda que essas expressões culturais não foram e não devem ser interpretadas, meridianamente, como a face visível de uma identidade. Tal como apreendidas nesta inventario, elas são mais eixos de possibilidades identitárias que expressões de identidades já consolidadas e reivindicadas. Não existe uma correspondência necessária entre expressões culturais e identidades, essas correspondências se constroem social e politicamente.

Ou seja, as identidades podem estar desvinculadas de certas práticas culturais locais e mais vinculadas a outras. Como exemplo temos o papel identitário das religiões afro-brasileiras, em geral praticadas por poucos mantenedores da tradição religiosa, mas que servem de símbolos definidores da cultura e identidade, como no Recôncavo baiano. O mesmo ocorre na região geoeconômica da Cotinguiba, com muita expressão na cidade de Laranjeiras, onde as danças de origem africana têm um peso simbólico na identidade da cidade, embora sejam mantidas por um número reduzido de grupos.

A cultura é um dos elementos fundantes na construção de um território identitário, conceito desenvolvido pela moderna geografia cultural (Claval, 1999; Haesbaert; 1997; Cosgrove, 1993), para dar conta das interfaces entre culturas e territórios. Nesse sentido, o território é habitado por culturas como também, os olhares forjados culturalmente sobre ele delimitam e dão vida aos territórios, criando territorialidades específicas. Assim, a distinção que fazemos entre identidades culturalmente determinadas e identidades políticas territorialmente determinadas, têm a ver com a forma privilegiada como os grupos sociais legitimam a solidariedade interna. Tal afirmação não é excludente, pois estas duas formas de legitimação identitária podem coexistir e se complementarem ou, ainda, legitimarem identidades diferentes. O fato é que essa distinção em nosso recorte analítico pode ser de grande valia para a compreensão da dinâmica do processo de construção de identidades locais e, também, dos Territórios de Planejamento do estado de Sergipe. Heranças e novas construções políticas e culturais abrem um viés interpretativo que podem nos auxiliar a entender o que está por trás de uma forma discursiva distanciada de se relacionar com as culturas locais ou ainda, entender a ausências de vinculo com essas culturas.

Ao termino da pesquisa nos indagamos: O que isso significou neste levantamento das expressões culturais da população do estado de Sergipe?

Em primeiro lugar, que este inventário não nos permite acessar automaticamente a identidade dos grupos, pois, como vimos, as expressões e manifestações culturais podem ou não serem produzidas em torno de identidades. Isso significa que o resultado do levantamento deve ser pensado de forma aberta e flexível, não como a base cultural da identidade do povo sergipano, mas sim como a expressão de como a cultura é pensada e praticada pela população, que produz culturas, i.e, práticas culturais, no seu dia-a-dia: às vezes de forma tradicional, focada na herança cultural, às vezes de forma ressignificada, seja de tradições seja de práticas contemporâneas e/ou globalizadas.

Em segundo lugar, isso significa também que as expressões culturais levantadas são, ao mesmo tempo, práticas e representações que marcam as experiências dos sujeitos, ao menos dos sujeitos abordados pela pesquisa, como também a base para repensar tais experiências. Pragmática e dialeticamente, isso significa que as expressões culturais são o resultado de ações e também meios para os atores repensarem suas ações.

Por exemplo, o bordado ou o artesanato no estado marcam a experiência de vida de muitos sergipanos ao mesmo tempo em que influencia sua forma de estar e de se projetar no mundo e influenciam seus projetos de futuro ao nível econômico, certamente, mas também ao nível das formas de sociabilidades, dos modelos familiares, das estratégias de transmissão dos saberes etc. 
Não por acaso, Leite (2003), ao estudar o artesanato sergipano, distinguiu quatro dimensões dessa manifestação cultural: uma dimensão social, que se reflete nos modos de vida de quem os produz; uma dimensão pedagógica, que se materializa nos saberes que se difundem e no conhecimento integral do saber-fazer; uma dimensão simbólica, que se externaliza no produto como bem cultural e, uma dimensão econômica, que se concretiza nas trocas, quando o artesanato é alçado à categoria de mercadoria. Por extensão, essas dimensões podem ser extrapoladas a um grande número de expressões culturais.

Em terceiro lugar, proporcionou a visibilidade de um inventário amplo de todos os municípios, que mesmo limitado em sua abordagem, demonstrou uma grandiosa matriz de culturas, diversa nos tipos, plural nos seus modos de fazer e dinâmica pela capacidade de criação e recriação dos fazeres, traduzindo um Sergipe de múltiplas formas, cores e ritmos.

A produção do material cartográfico dessa pesquisa insere-se no esforço recente de construção de uma cartografia cultural e, como tal, uma questão (ou provocação) merece ser anunciada: a pequena produção cartográfica de estudos culturais reflete uma desvalorização da cartografia enquanto instrumento valioso do conteúdo ou uma dificuldade na representação das realidades culturais abordadas, ou ainda ambas? Este trabalho e os passos demonstrativos da construção cartográfica elaborados para o Inventário Cultural realizado não têm a pretensão de responder a essas questões, mas certamente, abrem brechas e pistas indicativas do quanto ainda podemos produzir e mais facilmente comunicar, mostrar, demonstrar e explicitar pelo canal metafórico que matrizes, mapas e cartogramas nos oferecem.

A cartografia produzida constituiu, em última instancia, um produto circunscrito à uma linguagem, que se colocou aberto para estudos e aprofundamentos sobre o significado e as representações da cultura sergipana, mas que se mostra passível de aplicação a outros estudos. Ainda distantes de uma produção cartográfica atada à densidade da produção da geografia cultural, reafirmamos a importância de sua construção consonante aos conceitos e abordagem do estudo proposto.

\section{REFERÊNCIAS BIBLIOGRÁFICAS}

ALMEIDA, M. G. de. Uma leitura etnogeográfica do Brasil sertanejo In: SERPA, A. (org.) Espaços culturais - vivências, imaginações e representações.Salvador: Edufba, 2008. p. 313- 338.

CANCLINI, N. Culturas hibridas. São Paulo: EDUSP, 2003.

CLAVAL, P. Uma, ou Algumas, Abordagem (ns) Cultura (is) na Geografia Humana? In: SERPA, A. (Org.) Espaços culturais: vivências, imaginações e representações. Salvador: EDUFBA, 2008.

CLAVAL, P. A Geografia cultural. Florianopolis: EDUFSC, 1999.

COSGROVE, Denis. The Palladian Landscape: geographical change and its cultural representations in sixteenth century Italy. University Park: Pennsylvania State Univ., 1993.

DORTIER, Jean-François. Le dictionnaire des sciences humaines. Paris: Editions Sciences Humaines, 2008.

GEERTZ, C. A interpretação das culturas. Rio de Janeiro: LTC, 1989.

GOVERNO DE SERGIPE. Decreto 24338 de 20 de abril de 2007. Cria os Territórios de Planejamento.

HAESBAEERT, R. Des-territorialização e Identidade: a rede Gaúcha no Nordeste. Niterói: EDUFF, 1997

HAESBAEERT, R. Hibridismo, mobilidade e multiterritorialidade numa perspectiva geográfico-cultural integradora. In: SERPA, Ângelo (org.) Espaços culturais. Salvador: EDUFBA, 2008. p. 393-420.

HALL, S. A identidade cultural na pós-modernidade. Rio de Janeiro: DP\&A, 1999.

LEITE, R. P. Cultura popular e artesanato: dilemas do preservar e do consumir In: XI Encontro de Ciências Sociais do Norte e Nordeste. Anais. Aracaju:Anais, 2004.

MARTINELLI, M. Curso de cartografia temática. São Paulo: Contexto, 1991.

MORAES, A. C. R. de. Território e história no Brasil. São Paulo: Annablume, 2005. 
RAFFESTIN, C. Por uma Geografia do poder. São Paulo: Ática, 1993.

SANTOS, Milton. A natureza do espaço: espaço e tempo: razão e emoção. São Paulo: Hucitec, $3^{\text {a }}$ Ed. 1999.

VARGAS, M.A. M. \& NEVES, P. S. da C. Inventario de cada um dos oito territórios de Sergipe e elaboração de um Atlas da cultura sergipana. Relatório. Aracaju: UFS/ SEPLAN, 2009.

Trabalho enviado em agosto de 2011

Trabalho aceito em outubro de 2011 